\title{
Barriers to Career Progression: A Study of the Perceptions of Nepali Women Employees
}

\author{
Jyoti Regmi Adhikary* \\ School of Management, Kathmandu University, Lalitpur, Nepal
}

\begin{abstract}
Recent decades have witnessed unprecedented changes in workforce composition, resulting in women's increased involvement in the labor force. However, the proportion of women employees vary significantly within various organizational levels, with more women confined to junior level positions within organizations. This study, conducted in two phases, explored the career progression barriers as perceived by Nepali women employees to develop a set of 22-items questionnaire which was then used to examine how 114 women employees perceived those barriers in their career in management. Effort was also made to find if the perceived barriers were specific to any sub-group (position, job responsibility, and/or organization type). Findings of the study revealed that societal-related barrier was most prominent within which marriage during prime of career significantly hampered the career development of Nepali women employees. Further analysis indicated that the perceived barriers were not specific to any sub-group. These results have implications for organizations to improve policies and facilities in order to promote women's career progression. Limitations of the study are identified and suggestions for future results are discussed.
\end{abstract}

Keywords: Career progression barrier, Nepali women employees, women in employment

\section{Introduction}

Women employment has recently gained much attention from the perspective of career advancement. This is only natural in view of the fact that an increasing number of women are in the workforce, but only a very small percentage hold top level positions in business and public administration (Alvesson \& Billing, 2010). According to Ismail and Ibrahim (2008), even in traditional feminine professions such as social work and education, women do not occupy key decision-making jobs in proportion to their numbers, and tend to stay in doer position jobs. The absence of women in the highest and most visible positions is a significant issue, particularly because women have now become viable and valuable contributors to the workforce.

Maack and Passet (1994, as cited in Jones \& Oppenheim, 2002) opined that women's careers in the profession are hindered by restraints (social expectations and responsibilities placed on women that may limit their career potential), constraints (internalized patterns of behaviour and attitudes that result from gender socialization), and barriers (external variables as overt and covert discrimination that make entry or advancement in a field more difficult for women than men). Explaining these factors, some

* Author Email: jyoti@kusom.edu.np 
researchers focused on differences on career advancement between women and men (e.g., Mullan \& Harrison, 2008; Stanley, 2008), identifying reasons like age (e.g., McLay, 2008), seniority, training and experience (e.g., Moorosi, 2010), lack of mentor (e.g., Arifeen, 2010), work-life conflict (e.g., Ismail \& Ibrahim, 2008), self-limiting behaviour (e.g., Dickerson \& Taylor, 2000), self-imposed glass ceiling (e.g., Jones \& Oppenheim, 2002), and lack of career planning (e.g., Chugh \& Sanghal, 2007). Similarly, other researchers have concentrated on masculinized managerial practices (e.g., McTavish \& Miller, 2009), cultural values and expectations (e.g., Jamali, Sidani \& Safieddine, 2005), organizational policies and procedures (e.g., Buttigieg \& Walsh, 2000), and long hours culture (e.g., Ogden, McTavish, \& McKean, 2006).

Additionally, some studies are conducted to identify job specific barriers such as IT-related (e.g., Aaltio \& Huang, 2007), nursing (e.g., Stanley, 2008), and library profession (e.g., Jones \& Oppenheim, 2002). However, to the knowledge of the researcher, none of the extant literature in women in employment so far has stressed the hindrances of women's advancement in context of specific position, job responsibility, and/or organization type.

In Nepali context, not much effort has been done in identifying the career progression barriers for Nepali women employees. But, with the increasing participation of Nepali women in the formal employment sector (Central Bureau of Statistics [CBS], 2009), it is important that a better understanding of their career growth is developed. Taking a cue from Hofstede's (1998, as cited in Aaltio \& Huang, 2007) remarks on the ways in which management, organizational theory, and research itself are culturebound, the influence of traditional Nepali culture on the real experience of its women may be assumed to differ from the experience of their Western counterparts. This study is an attempt to provide explanation for the gender gap in career advancement prevalent in Nepali organizations by exploring the career progression barriers as perceived by Nepali women employees and identifying whether the perceived barriers are specific to various occupational and professional sub-groups.

\section{Theoretical Background}

\section{Women in Employment}

At the turn of the $18^{\text {th }}$ century, paid employment for women was the exception rather than the rule, and those women who did work outside the house did so only preliminary to marriage and the bearing of children (Russo \& Denmark, 1984, as cited in Tiefer, 1991). The authors further mentioned that although this pattern remained stable until about 1940, the World War II years were characterized by a dramatic influx of women into the labor force to fill jobs vacated by servicemen. Powell and Graves' (2003) study supports this by mentioning that the percentage of women working has been increasing since 1940, and the evidences of 2000 shows rising trend of women both participating in the workforce and achieving senior positions.

With growing tendency in the number of employed women, it could be expected that their representation in senior positions grows too. Although it is constantly growing, the number of women at high levels is still very small (Sujatha, 2008). Fairchild (2015) sheds light that though gender does not play a role in a person's ability to lead, women's representation in leadership positions has stagnated in recent years with only 25 companies in the Fortune 500 are run by women. Similarly, Scott (2014) highlights the proportion of women in senior roles is stuck at 24 percent. Regionally, Eastern Europe

and Southeast Asia lead the way on women in senior management, with 37 and 35 percent respectively. Of top leaders from mid-market businesses throughout the U.S., only 22 percent of senior 
managers were women (Scott, 2014), and women accounted for 16.6 percent of board members of large publicly listed companies in the 27 EU Member States (European Commission, 2013). These data reveal that developed countries have relatively fewer women in senior management as compared to developing countries. Across the Group of Seven industrialized nations, 21 percent of senior roles are held by women, compared with 32 percent in the BRIC economies. Russia has the highest proportion, at 43 percent and Japan is at the bottom with just nine percent of senior roles held by women.

On a different note, a meta-analysis of 45 studies comparing men and women on different leadership styles by Eagly, Johannesen-Schmidt, and van-Engen (2003) found the most effective model of leadership being transformational, and that women are more likely than men to adopt a transformational leadership style. Hence, it could be argued that women would do well if they led the world's major corporations. However, a review of the CEOs of major firms around the globe indicates that an actual resource with the potential needed in business is being neglected. In theorizing this situation, a social constructionist model on gender suggests that in the corporate world, as elsewhere, perception of behaviour of men and women are automatically filtered through a gendered lens and reconstituted within a more general discourse on gender difference itself (Stubbe, Holmes, Vine, \& Marra, 2000). Thus, despite women's increased presence and aspirations in management positions, executive leadership is still often seen to be synonymous with men.

\section{Barriers to Women for Career Progression}

Maskell-Pretz and Hopkins (1997) defined barrier as a factor, event or phenomenon that prevents or controls access to individuals from making progress, and it may be tangible or intangible, actual or perceived by the recipient. Researchers have categorized the barriers as internal and external (Cortis \& Cassar, 2005), or as glass ceiling and glass wall (Powell \& Graves, 2003), or as individual, organizational, and societal (Moorosi, 2010).

Socialisation is one theory put forward to explain the under-representation of women in senior positions. In line with this, women network advocates focus on building and exploiting informal and instrumental relationships to attain leadership roles. Similarly, Combs (2003) suggested the significance of informal more than formal socialization systems in advancing careers.

Role theory is another important concept to explain women's under-representation (Turner, 2002). This theory emphasizes the behaviours and activities appropriate for each sex. In this line, Chugh and Sahgal (2007) examined the literature of the last two decades on career advancement and leadership to unearth the impediments for women employees. Their review revealed that sex role orientation and the stereotyping of a manager's role as a masculine construct are predominant themes that significantly influence women's advancement to the top echelons in organizations.

A comparative study on career progression among women from Australia and Mauritius by Thanacoody, Bartram, Barker, and Jacobs (2006) identified a number of barriers to female advancement. In this study, Thanacoody et al. (2006) have also referred to various barriers identified by previous scholars. A few examples of barriers mentioned are masculine organisational culture (White, 2003), work and family imbalances (Ward \& Wolf-Wendel, 2004), and gender power imbalance in the workplace (Oakley, 2000).

Several studies have argued barriers to be job specific. One such study on nursing career by Mullan and Harrison (2008) indicated organisational compared to individual barriers slow the career progression

of female nurses. Review by Stanley (2008) in a similar study found that organizational structure and 
culture increased barriers to female advancement up the career ladder. Similarly, survey by Buttigieg and Walsh (2000) among bank employees in Australia and Britain found that to achieve promotion, women had to conform to more stringent, performance-based criteria than did their male counterparts. Jones and Oppenheim's (2002) study on UK library profession concluded that for many women, the glass ceiling is imposed by themselves. It further noted that it is often their choice to take a career break to put the needs of their family first before their own career ambitions.

Similar results are reported in academic profession too. For example, Moorosi's (2010) study in South African secondary school, found female principals' experiences of their career route to the principalship are influenced by personal, organizational, and social factors. McLay's (2008) study about head-teacher career paths of men and women in UK schools identified taking career breaks to have children and tendency of gradually building up confidence and experience before seeking headship as a disadvantage to women.

McMahon, Limerick, Cranston, and Andersen (2006) tried to document women's reflections on their careers over a ten-year period. They categorized the barriers impacting women's careers as age, familywork balance decisions, personality, gender bias, departmental structure, organizational policy, and geographical location. These authors also analysed barriers for women at various levels and highlighted the importance to assume that under-representation and constraints experienced by Asian women employees throughout their career are similar to those reported worldwide.

\section{Nepali Women Employees}

Though the precise information of women involvement in employment is not available, Nepal labor force survey carried out in the year 2008 by the CBS (2009) estimated that the legislators, senior officials, and professional level women altogether is about 48000 (i.e., 24 percent) out of a total 197000 personnel within these three occupational categories. This number is only nine percent of the total Nepali women working as paid employees.

Within paid occupation, the highest percent of women employees is within elementary occupation (i.e., 54 percent), followed by women employees as technicians and associate professionals (i.e., 14 percent). And, the lowest percent of women employees is within the legislators and senior official levels (i.e., 0.38 percent). Although the number of Nepali women working is in the increasing trend, there is lack of data indicating exact number of Nepali women involved in managerial jobs. Compared with previous labor survey, CBS (2009) report that gender segregation within management functions still remains same as before, the discrepancy between males and females representation at senior and executive levels remaining problematic.

\section{Methods}

One major research issue of this study was to explore the career progression barriers as perceived by Nepali women employees. This would require subjective interpretation of the respondents' experiences which could be best captured through in-depth interview. Another major research issue was to identify whether the career progression barriers are specific to various career subgroups which required collection of information from specific areas. For this, questionnaire survey was considered an appropriate approach. Therefore, this study was conducted in two phases. The first phase of the research helped to explore the subjective aspects of career progression barriers through Nepali women employees' 
experiences. And, the second phase helped to identify and maximize the generalizability of the barriers specific to various career subgroups.

\section{Study One}

Five women managers, one each from five different sectors, viz.: banking, academic, INGO, semigovernment, and service, were selected to share their experiences about the barriers they perceived and faced during their careers. According to the CBS (2009), not only the representation of women in these sectors is more, but also there is an increasing trend of Nepali women joining these sectors as compared to other employment sectors. The five women were purposively selected considering their suitability to answer the questions directed by the study, particularly from the perspective of their experience with the various phases of career advancement and the different barriers they had faced while climbing their career ladders.

The sample varied in terms of age, ethnicity, academic qualification, and organizational rank. They ranged in age from 35 to 44 years with an average age of 40.8 years. They represented middle and upper levels of management positions. All had masters or above educational degrees. All five were married, four with one child while one with two.

Study one was based on interviews (telephone and face to face) where the interviewees were asked to narrate their detailed experiences on their career paths. Probes including phrases such as "What do you mean by.....?" and "Tell more about...." were used to request the respondents to elaborate their answers.

Responses by each respondent were separately listed in different sheets. Following a simpler version of content analysis, similar nature of the responses were then shortlisted and placed in a second sheet as a first common list of items. Simultaneously, different sheets were prepared comprising the items generated from literature review on career progression barriers for women. These items were then listed in a second common list of items to draw the commonality among items from literature review. A third common list was then prepared comparing the first and second common item sheets. Finally, a list of 22 items was generated also including the items not found in the reviewed literature but mentioned by the interviewees. These items were verified with the established constructs and categorized as individual-related, organizational-related, and societal-related barriers. The 22 items are shown in Table 4.

A questionnaire set was formed including the 22 items on career progression barriers. Suggestions from various sources were incorporated to revise and modify the questionnaire. The questionnaire was then pilot-tested with a group of 20 women employees. The reliability of this scale estimated by Cronbach's alpha was 0.86 which was considered adequate reliability.

Study Two

Six different organization types (banking and finance, academic, I/NGO, developmental, service, and semi-government) from private and public sectors were selected for second phase. Selection of these sectors was again purposive because representation of Nepali women employees is more in these sectors compared to many other sectors (CBS, 2009). At least 20 women employees each from six organizations were given the questionnaire sets. The selection of the respondents was on the basis of convenience sampling. Out of 180 questionnaires distributed, a total of 130 were returned. After a careful scrutiny, 114 valid questionnaires formed the sample for this study. The respondents were asked to respond to 22 items on a 5-points Likert scale ( $1=$ Strongly Disagree to 5= Strongly Agree). 


\section{Results}

For analysis, frequency and percentage calculations were conducted for demographic variables of the respondents. Details of this information are exhibited in Table 1. The variable-wise mean scores were computed in order to identify the importance attached by the respondents towards the various variables. Percentage calculations of the women employees perceiving the variables as important also helped to identify their perception on each variable as well as the group of variables. One way analysis of variance was undertaken to identify if the factors vary according to position, job responsibility, and/or organization type.

\section{Factors affecting Promotion and Job Change}

To understand Nepali women's career aspirations, it was necessary to know two important things about their jobs among many others. One was whether they wanted promotions or not, and the other was the important factors they had to consider if they changed their jobs during any time in their career. Since studies have linked promotions with career advancement (Forret \& Dougherty, 2001), any factor restricting promotions would be considered as barriers for career advancement. Also, studies have indicated that mostly employees change their jobs for better opportunities (e.g., Ismail \& Ibrahim, 2008; Moorosi, 2010). But for many women, apart from career advancement, there could be more reasons why they had to, or could not change their jobs. When these results are linked with the factors women employees perceive as barriers, a better understanding could be made about the hurdles for Nepali women for career progression.

To the question on promotion, out of 90 who responded, all except three mentioned that they wanted promotion. For not wanting promotion, reasons given were: lack of qualification, recent promotion, and the new job. The survey clearly indicated that almost all women wanted to move forward in their careers. Table 2 exhibits factors respondents perceived important for promotion.

The study explored the reasons why women employees changed their jobs. Findings suggest that out of 44 percent respondents who changed their job/s, more than half did for exposure and to explore better opportunities, while other reasons as mentioned are exhibited in Table 3.

\section{Perception on Barriers among Women Employees}

Twenty two variables identified as career progression barriers by Nepali women managers were tested for their impact (according to their importance) on the career advancement for Nepali women working in different organizations.

In order to understand certain characteristics of the variables, the variable-wise means scores (highest to lowest within the grouping) according to the perceived importance are presented in Table 4 . The mean score of 3.89 for marriage during prime of career shows that the Nepali women employees perceive this variable significantly affecting the progress of their career. This is further supported from the mean scores on family role being a primary obligation $(\mathrm{M}=3.68)$, avoiding transfers on jobs $(\mathrm{M}=3.36)$, resistance to work beyond office hours $(\mathrm{M}=3.05)$, and lacking exposure and opportunities for progress $(\mathrm{M}=3.02)$. The respondents perceived lack of ambition in workplace $(\mathrm{M}=1.97)$ as factor least relevant to their career growth.

The variables were categorized into three different groups based on the literature review. Grouping is shown in Table 4. The group-wise mean scores showed that Nepali women employees perceived societal-related barriers $(\mathrm{M}=2.99)$ more relevant hindrance for their career progression than organizational $(M=2.75)$ and individual $(M=2.67)$ related barriers. 
Table 1

Socio-demographic Profile of Respondents

\begin{tabular}{|c|c|c|}
\hline \multicolumn{2}{|l|}{ Variables } & \multirow{2}{*}{$\begin{array}{r}\text { Frequency }(\%) \\
40(36.4)\end{array}$} \\
\hline Age & Below 30 & \\
\hline & $30-40$ & $54(49.0)$ \\
\hline & Above 40 & $16(14.6)$ \\
\hline \multirow[t]{4}{*}{ Marital Status } & Single & $73(64.0)$ \\
\hline & Married & $36(31.6)$ \\
\hline & Divorced & $3(2.6)$ \\
\hline & Separated & $2(1.8)$ \\
\hline \multirow[t]{3}{*}{ Education } & Intermediate & $10(8.8)$ \\
\hline & Bachelor & $36(31.6)$ \\
\hline & Master & $68(59.6)$ \\
\hline \multirow[t]{5}{*}{ Caste } & Brahmin & $33(28.9)$ \\
\hline & Chhettri & $26(22.8)$ \\
\hline & Newar & $40(35.1)$ \\
\hline & Other Janajati & $13(11.4)$ \\
\hline & Dalit & $1(0.9)$ \\
\hline \multirow[t]{3}{*}{ No of Children } & One & $29(25.4)$ \\
\hline & Two & $31(27.2)$ \\
\hline & More than two & $2(1.8)$ \\
\hline \multirow[t]{6}{*}{ Organization Type } & Banking and finance & $20(17.5)$ \\
\hline & Academic & $17(14.9)$ \\
\hline & I/NGO & $21(18.4)$ \\
\hline & Developmental & $21(18.4)$ \\
\hline & Service & $19(16.7)$ \\
\hline & Semi government & $16(14.0)$ \\
\hline \multirow[t]{5}{*}{ Position } & Support & $27(23.7)$ \\
\hline & Officer & $52(45.6)$ \\
\hline & Managerial & $15(13.2)$ \\
\hline & Executive & $4(3.5)$ \\
\hline & Teaching staff & $16(14)$ \\
\hline \multirow[t]{7}{*}{ Major Responsibility } & Administrative & $23(20.4)$ \\
\hline & Finance & $14(12.4)$ \\
\hline & Marketing & $8(7.1)$ \\
\hline & Management & $21(18.6)$ \\
\hline & Customer service & $16(14.2)$ \\
\hline & Teaching & $15(13.3)$ \\
\hline & Technical & $16(14.2)$ \\
\hline
\end{tabular}


Table 2

Important factors for promotion

\begin{tabular}{lr}
\hline Factors & Frequency (\%) \\
\hline Better performance, hard work, commitment & $38(33.3)$ \\
Training for skill enhancement & $21(18.4)$ \\
Exposure, education, confidence & $16(14.0)$ \\
Organizational support & $10(8.8)$ \\
Communication, network & $5(4.4)$ \\
\hline
\end{tabular}

Table 3

Important factors for changing the jobs

\begin{tabular}{lr}
\hline Factors & Frequency (\%) \\
\hline Exposure and to explore better opportunities & $26(52)$ \\
Career development & $17(34)$ \\
Financial benefits & $6(12)$ \\
Child rearing/ family responsibilities & $4(8)$ \\
Better working environment & $4(8)$ \\
Job satisfaction & $4(8)$ \\
Job security & $3(6)$ \\
Project completion & $3(6)$ \\
\hline
\end{tabular}

Total percent of women showing agreement for each of the items is also shown in Table 4. Many of the items in the questionnaire were associated with individual-related barriers. Five items were related to the organizational situation, which covers organizational practices and policies, and work environment. In terms of societal-related barriers, women employees appeared to know where they stand in the societal/family structure and that they have their parts to play. As such, when it comes to household duties, 78.1 percent of the women employees agreed that women should not shirk their household responsibilities in chasing their career. This is in accordance with the role theory (Turner, 2002). Furthermore, they also agreed that they are married during the prime of their career ( 86.2 percent) which often requires them to sacrifice their career for family/society. The conditioning in society has resulted in a situation where women employees think that they are perceived as being less committed to work than their male counterparts (39.9 percent). Over half of the respondents agreed that family is biased while providing higher education for them (52.7 percent) which ultimately result in lack of exposure and opportunity (54.5 percent) for career progression.

Perception on Barriers among Organizational Sub-Groups

To identify how women employees within the sub-groups perceive barriers, mean scores were calculated that are exhibited in Table 5. Within organization type, respondents from all six organization types perceive societal-related barriers more pertinent as compared to individual- and organizational-related barriers. The highest mean from semi-government sector $(M=3.27)$ was statistically significant at $p$ <.05. Within this sub-group, respondents from banking and financial sector $(\mathrm{M}=2.43)$ perceived individual-related barriers as least relevant for their career progression. 
Table 4

Group wise mean scores and perception of barriers

\begin{tabular}{|c|c|}
\hline Items & Mean Score (\% agree) \\
\hline Individual Related Barriers & 2.67 \\
\hline Women avoid job transfers & $3.36(68.4)$ \\
\hline Women lack the access to informal communication and networks & $3.18(60.4)$ \\
\hline Women resist working beyond office hours & $3.05(56.7)$ \\
\hline $\begin{array}{l}\text { Women are unwilling to participate in parties/business meetings after office } \\
\text { hours }\end{array}$ & $2.89(46.5)$ \\
\hline Women avoid taking risk in workplace & $2.72(41.2)$ \\
\hline Women are happy just having a job & $2.64(41.2)$ \\
\hline Women lack higher education for career advancement & $2.48(38.9)$ \\
\hline Women hesitate to show extra talents they have & $2.31(24.5)$ \\
\hline Women usually lack job related skills and potentials & $2.06(17.7)$ \\
\hline Women lack ambition in workplace & $1.97(14.2)$ \\
\hline Organizational Related Barriers & 2.75 \\
\hline Organization promotes employees based on other criteria than performance & $3.05(54.9)$ \\
\hline Initial hiring for women starts at lower level & $2.91(49.1)$ \\
\hline Male superiors in workplace are not friendly to women & $2.76(40.7)$ \\
\hline Organization policies are not favorable for women & $2.73(39.6)$ \\
\hline Environment in the organization is not suitable for women & $2.35(27.5)$ \\
\hline Societal Related Barriers & 2.99 \\
\hline Women are married during the prime of their career & $3.89(86.2)$ \\
\hline Family role is a main responsibility for women & $3.68(78.1)$ \\
\hline Women lack exposure and opportunities for progress & $3.02(54.5)$ \\
\hline Family is biased while providing higher education to women & $2.97(52.7)$ \\
\hline Performance of women in workplace is perceived low & $2.70(44.9)$ \\
\hline Women are perceived not suitable for higher jobs & $2.38(34.0)$ \\
\hline Women are perceived to be less committed at workplace & $2.34(33.9)$ \\
\hline
\end{tabular}

Similarly, within position sub-group too, respondents from all five positions perceived societalrelated barriers more significant for their career progression. Within the categories of barriers, women in support level position perceived the barriers as less pertinent to their progression unlike the perception of women in managerial position with highest mean score $(\mathrm{M}=2.99)$ in case of individual-related barriers, and women in executive level position with highest mean score $(M=2.90)$ in case of organizationalrelated barriers. 
Table 5

Mean scores among sub-groups within organizations

\begin{tabular}{lccc}
\hline Sub-groups & $\begin{array}{c}\text { Individual-related } \\
\text { barrier }\end{array}$ & $\begin{array}{c}\text { Organizational } \\
\text { related }\end{array}$ & $\begin{array}{c}\text { Societal-related } \\
\text { barrier }\end{array}$ \\
\hline Organization type & & & \\
Semi-government & 3.14 & 2.79 & 3.27 \\
Service & 2.52 & 2.84 & 3.13 \\
Academic & 2.80 & 2.61 & 3.07 \\
I/NGO & 2.61 & 2.91 & 3.05 \\
Banking \& finance & 2.43 & 2.70 & 2.85 \\
Developmental & 2.57 & 2.66 & 2.68 \\
Position & & & \\
Support & 2.37 & 2.64 & 2.75 \\
Officer & 2.75 & 2.84 & 3.06 \\
Managerial & 2.99 & 2.79 & 3.00 \\
Executive & 2.83 & 2.90 & 3.05 \\
Teaching staff & 2.74 & 2.63 & 3.19 \\
Job responsibility & & & \\
Administrative & 2.61 & 2.96 & 2.83 \\
Finance & 2.64 & 2.46 & 3.05 \\
Marketing & 2.61 & 3.03 & 3.39 \\
Management & 2.70 & 2.72 & 2.84 \\
Customer service & 2.31 & 2.73 & 2.81 \\
Teaching & 2.77 & 2.65 & 3.13 \\
Technical & 3.03 & 2.67 & 3.29 \\
\hline
\end{tabular}

Within major job responsibility sub-groups, women staff in administration perceived organizationalrelated barriers $(M=2.96)$ more relevant, whereas women staff in finance area perceived societal-related barriers $(M=3.05)$ as most relevant for their career progression. Likewise, societal-related barriers were more relevant barriers for women employees with other responsibilities too with the highest mean score being for women in marketing job $(\mathrm{M}=3.39)$. Within this sub-group, women in customer service job $(\mathrm{M}=2.31)$ perceived individual-related barriers and women in finance job $(\mathrm{M}=2.46)$ perceived organizational-related barriers comparatively not so relevant for their career progression.

To investigate and identify significant differences in perceptions about barriers among the various sub-groups in the organization, one-way ANOVAs were done. The respondents were grouped into three sections: organization type, position in the organization, and major job responsibilities. Upon analyzing the mean comparison tests, major job responsibility analysis found that there were no significant differences among the groups, while organization type and position-wise analyses suggested that there was statistically significant ( $\mathrm{p}<.05)$ difference among the groups in case of individual level barriers. Also, there was statistically significant $(\mathrm{p}<.05)$ difference in perception of barriers within women from officer and managerial positions. The results of significant difference are shown in Tables 6 and 7. 
Barriers to Career Progression 27

Table 6

One-way ANOVA of barriers according to different organization types

\begin{tabular}{|c|c|c|c|c|c|c|c|c|c|}
\hline & \multirow[b]{2}{*}{ Item } & \multirow[b]{2}{*}{ Mean } & \multicolumn{7}{|c|}{ Mean difference } \\
\hline & & & SD & 1 & 2 & 3 & 4 & 5 & 6 \\
\hline 1 & Banking \& finance & 2.43 & 0.73 & - & -0.37 & -0.18 & -0.13 & -0.09 & $-0.71 *$ \\
\hline 2 & Academic & 2.80 & 0.88 & & & 0.19 & 0.24 & 0.28 & -0.34 \\
\hline 3 & I/NGO & 2.61 & 0.46 & & & & 0.05 & 0.09 & $-0.53^{*}$ \\
\hline 4 & Development & 2.56 & 0.50 & & & & & 0.04 & $-0.58 *$ \\
\hline 5 & Service & 2.52 & 0.58 & & & & & & $-0.62 *$ \\
\hline 6 & Semi-government & 3.14 & 0.74 & & & & & & - \\
\hline
\end{tabular}

Note: $* p<.05$

Table 7

On-way ANOVA of barriers according to position

\begin{tabular}{llccccccc}
\hline & & & \multicolumn{5}{c}{ Mean difference } \\
& Item & Mean & SD & 1 & 2 & 3 & 4 & 5 \\
\hline 1 & Support & 2.37 & 0.69 & - & $-0.47^{*}$ & -0.05 & -0.46 & -0.37 \\
2 & Officer & 2.84 & 0.58 & & & $-0.42^{*}$ & 0.10 & 0.10 \\
3 & Managerial & 2.42 & 0.58 & & & & -0.41 & -0.32 \\
4 & Executive & 2.83 & 0.50 & & & & & -0.10 \\
5 & Teaching staff & 2.74 & 0.90 & & & & & - \\
\hline
\end{tabular}

Note: $* p<.05$

\section{Discussion}

Empirical evidences drawn from numerous studies (e.g., Aaltio \& Huang, 2007; Omar \& Davidson, 2001) have indicated that the experiences of women in management across national boundaries are similar to a certain extent. Nevertheless, some clear differences exist across national boundaries due to cultural uniqueness. In comparing the findings to those of the West, it is evident that in Western societies, marriages, families, and careers do not go hand-in-hand for women managers. Research on women managers in Asia on the other hand have revealed that remaining single or being married but childless are options that many Asian women may not be willing to emulate (Omar \& Davidson, 2001). In many cases, Nepali women have no real choices between having careers or families, as marriages and motherhood are social imperatives. Women in Nepal, for example, may face greater challenges due to the more traditional orientations of society. Thus, in the study of women as employees, culture does matter.

Findings of this study revealed that career progression for Nepali women employees in various sectors is hampered by the individual, organizational, and societal structures that govern them. One major barrier is the marriage during prime of career. The study also divulges the fact that it is mostly women who have to face the problem arising out of work and family balance, which is substantiated from the high mean scores on items such as family role being main responsibility, job transfers avoidance, resistance working beyond office hours, as well as women lack exposure and opportunities for progress. These findings support the reference of Aaltio and Huang (2007) on Hofstede's (1984, 
1991, 1998) cross-culture works that all Asian cultures are collective and familial, expecting women to assume primary responsibility for the family. This is further substantiated by the fact that societal-related barriers were perceived to affect more adversely to their career progression.

The study signifies that Nepali women employees yearn for progression in their career in management. The respondents indicated that moving in their career is facilitated by their own hard work and performance as well as trainings for skill enhancement, education, and exposure that make them confident, which is consistent with the findings of Tharenou (2001) that identified the human capital factors (education, skills, knowledge, and work experience) as strongest predictors of advancing in management for women. This would suggest that the exposure and opportunity in organizational and in personal context would help Nepali women build confidence to perform better for career growth. This is further strengthened by what women employees have reported about the reasons for changing their jobs.

Women employees from semi-government organizations perceived individual-related barriers significantly more vital while women from banking and financial sector perceived same barriers as least important for their career advancement. This phenomenon can be explained by the concept of attribution in social perception (Luthans, 2011). Prevailing women friendly quota system in semi-government sector is more likely to provide opportunity to women employees from that sector to enjoy positive discrimination. Hence, according to dispositional attribution concept, they attribute individual-related factors as more important. However, according to situational attribution concept, women in banking and finance sector who face tough organizational environment and procedures, are more likley to blame the external factors (organizational and societal related factors) for hindering their progress in career.

The analysis exhibited that women in officer level position perceive individual-related barriers as less significant for their career progression than perceived by women from managerial position and women from support level position. One way to explain this is that at the managerial level, women are expected to be self-competent while for women at lower position as support level, since their job may not require high skill and competency for performance, they can afford to be less competent. But, at officer level position, being in between, chances are high that women perceive their own capabilities (individual-related factors) as hindrance for moving up the career.

The ANOVA results showed that women working in administrative jobs perceive organizationalrelated barriers as most prominent whereas, the women in other responsibility areas perceive the societalrelated barriers as most prominent barriers. An argument for this could be that the decisions one has to make in administrative job are more influenced by organizational policies and procedures than decisions by the employees in other responsibility areas. So, it would be natural for women in administrative responsibility to perceive organizational-related factors as more important barriers for advancement.

\section{Implications and Directions for Future Research}

It is apparent from the study that if we are to promote career progression of women in management, change is needed at three levels. First, the importance of change at the societal level was emphasized as major part of the barriers for Nepali women employees. While a fundamental transformation in societal or cultural values is not expected and probably not warranted, there are certain aspects that can be addressed. The role of family and civic education can be stressed. Education has been emphasized as a key venue for change, both at the level of family and organization in many research studies. One such study by Jamali, Sidani and Safieddine, (2005) suggest that education can nurture values of equity, 
fairness, and mutual respect. Moreover, education has indeed been consistently shown to positively influence not only self-image and confidence but also patterns of labour force participation.

The second level at which the constraints facing Nepali women employees can be addressed is organizational support. Nepali organizations need to be ready to confront the challenge and responsibility of identifying and developing high potential employees and providing adequate developmental opportunities, irrespective of gender. Organizational processes need to be inclusive of women talent in order to leverage the intellectual capital of the entire workforce (Kerai \& Mukulu, 2012). Perhaps there is the need of corporate support mechanism and measures to provide an encouraging work environment where women can develop and realize their full potential.

The third venue for tackling and addressing the constraints facing Nepali women at work is action at the individual level where the change has to be catalyzed by women themselves. In the long run, people cannot continue to question women's reliability and commitment to their work and organizations if they demonstrate sustained competence, commitment, perseverance, and dedication. Therefore, much responsibility lies in the hands of women to overcome the barriers that hinder their career progression.

The implications of this study are equally relevant for research too. Little is known in scholarly literature about the specific challenges that Nepali women employees have encountered in their careers. Being the first of this kind in Nepal, this study will help broaden the sphere of extant Nepali literature regarding women in employment. Additionally, this study confirms with the many earlier studies that like management theories, research is culture bound (Hofstede, 1998, as cited in Aaltio \& Huang, 2007). Also, the results support earlier findings that women from whichever part of the world, do face numerous barriers for career advancement, what differs are the context and the magnitude (e.g., Sujatha, 2008).

The results of the present study should be interpreted in light of various limitations. The sample selection and coverage makes the results difficult to generalize. Study one included a sample of highly educated, full-time managerial and professional women. Whether the questionnaire developed through the perception of those women would be justified to identify and generalize the perception of less educated women in various hierarchical positions would be a major concern. Perhaps, a more judicious approach would have been either to use already validated instrument instead, or, conduct the entire study through qualitative method increasing the number of respondents for in-depth interview. Also, factor analysis would have been a better approach to categorize the items. However, the researcher had to depend on limited literature reviews to categorize the variables into three groups.

Despite various limitations and constraints, this study has contributed to our understanding of career progression generally, by its specific examination of the perceived barriers encountered by Nepali women employees. In the absence of similar research in context of Nepali women, the findings could add value to the existing literature as well as identify significant implications for various organizations in Nepal. As the study compares the perception of barriers among various sectors, positions, and job responsibilities, there is an opportunity to ascertain the relative importance of the barriers to advancement for Nepali women employees and hence conduct comparative study with women in terms of different sectors, positions, and responsibility areas.

There are several possibilities to extend this research project. Further in-depth research is needed that looks specifically at the relative experiences of men and women employees in career progression. This might call for a longitudinal and qualitative approach that, through a gender lens, tracks the factors perceived to hinder career development over a period of time and at various stages of their careers. Also, there is an opportunity to conduct comparative research between women employees across different 
occupational sectors and job responsibilities to ascertain the relative importance of the barriers to advancement for women employees in a particular position (for example, managerial) with women in similar positions in other sectors and responsibility areas assisting the organizations to deal with the barriers more collaboratively. And, many other organizations could take learning lessons from them to facilitate women advancement and empowerment. Yet, another area for improvement would be to identify the facilitators and enablers along with the barriers for career progression for women employee. This would provide a positive flavour to the present research study.

Lastly, a supplementary research with those women who have achieved executive level positions is required to explore in more depth their career patterns and the factors that have contributed to their success stories and any sacrifices they might have had to make along the way. This might provide practical advice to other women on how they can best ascend the organizational hierarchy. It is expected that such a study will help fill the gaps of the present research and seek answers for many questions not answered in the present study.

\section{References}

Aaltio, I., \& Huang, J. (2007). Women managers' careers in information technology in China: high flyers with emotional costs? Journal of Organizational Change Management, 20(2), 227-244. http://dx.doi.org/10.1108/09534810710724775

Alvesson, M., \& Yvonne Due Billing, Y. D. (2010). Understanding Gender and Organizations. Journal of Industrial Relations, 52(4), 526-528.

http://dx.doi.org/10.1177/00221856100520040703

Arifeen, S. R. (2010). The significance of mentoring and its repercussions on the advancement of professional, managerial women in Pakistan. Global Business Review, 11(2), 221-238. http://dx.doi.org/10.1177/097215091001100207

Buttigieg, D., \& Walsh, J. (2000). How do women fare in internal labour markets? Evidence from the Australian and British banking industries. The Journal of Industrial Relations, 42(3), 351-365. http://dx.doi.org/10.1177/002218560004200302

Central Bureau of Statistics (2009). Report of the Nepal Labour Force Survey 2008. Kathmandu, Nepal: Author

Chugh, S., \& Sahgal, P. (2007). Why do few women advance to leadership positions? Global Business Review, 8(2), 351-365. http://dx.doi.org/10.1177/097215090700800211

Combs. G. M. (2003). The duality of race and gender for managerial African American women: Implications of informal social networks on career advancement. Human Resource Development Review, 2(4), 385-405. http://dx.doi.org/10.1177/1534484303257949

Cortis, R., \& Cassar, V. (2005). Perceptions of and about women as managers: investigating job involvement, self-esteem and attitudes. Women in Management Review, 20(3), 149-164. http://dx.doi.org/10.1108/09649420510591834

Dickerson, A., \& Taylor, M. A. (2000). Self-limiting behavior in women self-esteem and self-efficacy as predictors. Group \& Organization Management, 25(2), 191-210. http://dx.doi.org/10.1177/1059601100252006

Eagly, A. H., Johannesen-Schmidt, M. C., \& van-Engen, M. L. (2003). Transformational, transactional, and laissez -faire leadership styles: A meta analysis comparing women and men. Psychological Bulletin, 129(4), 569-591. http://dx.doi.org/10.1037/0033-2909.129.4.569 
European Commission. (2013). Women and men in leadership positions in the European Union. Belgium: Author http://dx.doi.org/10.2838/50821

Fairchild, C. (2015). Why so few women are CEOs. Retrieved from: http://fortune.com/2015/01/14/whyso-few-women-ceos/

Forret, M. L., \& Dougherty, T. W. (2001). Correlates of networking behavior for managerial and professional employees. Group \& Organization Management, 26(3), 283-311. http://dx.doi.org/10.1177/1059601101263004

Ismail, M., \& Ibrahim, M. (2008). Barriers to career progression faced by women: Evidence from a Malaysian multinational oil company. Gender in Management: An International Journal, 23(1), 5166. http://dx.doi.org/10.1108/17542410810849123

Jamali, D., Sidani Y., \& Safieddine, A. (2005). Constraints facing working women in Lebanon: an insider view. Women in Management Review, 20(8), 581-594. http://dx.doi.org/10.1108/09649420510635213

Jones, E., \& Oppenheim, C. (2002). Glass ceiling issues in the UK library pnrofession. Journal of $\begin{array}{llll}\text { Librarianship and } \quad \text { Information } & \text { Science, } & 34(2), & 103-115 .\end{array}$ http://dx.doi.org/10.1177/096100060203400205

Kerai, MN. \& Mukulu, E. (2012). Perceived organizational barriers to women career progression in Kenya's civil service. International Journal of Advances in Management \& Economics, 1(6), 203213.

Luthans, F. (2011). Organizational behaviour (12 ${ }^{\text {th }}$ ed.). New Delhi: McGraw-Hill.

Maskell-Pretz, M., and Hopkins, W. E. (1997). Women in engineering: Toward a barrier-free work environment. Journal of Management in Engineering, 1(2), 32-37. http://dx.doi.org/10.1061/(ASCE)0742-597X(1997)13:1(32)

McLay, M. (2008). Headteacher career paths in UK independent secondary coeducational schools: Gender issues. Educational Management Administration \& Leadership, 36(3), 353-372. http://dx.doi.org/10.1177/1741143208090594

McMahon, M., Limerick, B., Cranston, N., \& Andersen, C. (2006). Going up? Women in the public $\begin{array}{llll}\text { sector. Career Development } & \text { International, } & \text { 11(7), }\end{array}$ http://dx.doi.org/10.1108/13620430610713472

McTavish, D., \& Miller, K. (2009). Gender balance in leadership? Reform and modernization in the UK further education sector. Educational Management Administration \& Leadership, 37(3), 350-365. http://dx.doi.org/10.1177/1741143209102784

Moorosi, P. (2010). South African female principals' career paths: Understanding the gender gap in secondary school management. Educational Management Administration \& Leadership, 38(5), 547562. http://dx.doi.org/10.1177/1741143210373741

Mullan B., \& Harrison, J. (2008). Male and female nursing applicants' attitudes and expectations towards their future careers in nursing. Journal of Research in Nursing, 13(6), 527-539. http://dx.doi.org/10.1177/1744987107085500

Oakley, J. G. (2000). Gender-based barriers to senior management positions: Understanding the scarcity of female CEOs. Journal of Business Ethics, 27(4). 321-334. http://dx.doi.org/10.1023/A:1006226129868

Ogden, S. M., McTavish, D., \& McKean, L. (2006). Clearing the way for gender balance in the management of the UK financial services industry Enablers and barriers. Women in Management Review, 21(1), 40-53. http://dx.doi.org/10.1108/09649420610643402

Omar, A., \& Davidson, M. J. (2001). Women in management: a comparative cross-cultural overview. Cross Cultural Management: An International Journal, 8(3/4), 35-67. 
http://dx.doi.org/10.1108/13527600110797272

Powell, G. N. \& Graves, L. M. (2003). Women and men in management ( $3^{\text {rd }}$ ed.). Thousand Oaks, London: Sage.

Scott, M. E. (2014). Number of women in senior management stagnant at $24 \%$. Retrieved from: http://forbes.com/sites/forbesasia/2014/03/06/number-of-women-in-senior-management-stagnantat-24/

Stanley, D. (2008). Male and female nursing applicants' attitudes and expectations towards their future careers in nursing. Journal of Research in Nursing, 13(6), 540-541. http://dx.doi.org/10.1177/1744987107085532

Stubbe, M., Holmes, J., Vine, B., \& Marra, M. (2000). Forget Mars and Venus, let's get back to earth!: Challenging gender stereotype in workplace. In J. Holmes (Ed). Gendered Speech in Social Context: Perspectives from Gown and Town, (pp. 231-258). Wellington: Vitoria University Press

Sujatha, R. (2008). Barriers in career growth of women managers: An Indian scenario. Asia-Pacific Business Review, 4(3), 108-116. http://dx.doi.org/10.1177/097324700800400313

Thanacoody, P. R., Bartram, T., Barker, M., \& Jacobs, K. (2006). Career progression among female academics: A comparative study of Australia and Mauritius. Women in Management Review, 21(7), 536-553. http://dx.doi.org/10.1108/09649420610692499

Tharenou, P. (2001). Going up? Do traits and informal social processes predict advancing in management? The Academy of Management Journal, 44(5), 1005-1017. http://dx.doi.org/10.2307/3069444

Tiefer, L. (1991). A brief history of the association for women in psychology: 1969-1991. Psychology of Women Quarterly, 15(4), 635-649. http://dx.doi.org/10.1111/j.1471-6402.1991.tb00436.x

Turner, R. H. (2002). Role Theory. In J. H. Turner (Ed.) Handbook of Sociological Theory, (pp. 233254). New York: Kluwer Academic / Plenum Publishers

Ward, K., \& Wolf-Wendel, L. (2004). Academic motherhood: Managing complex roles in research universities. Review of Higher Education, 27(2), 233-257. http://dx.doi.org/10.1353/rhe.2003.0079

White, K. (2003). Women and leadership in higher education in Australia. Tertiary Education and Management, 9(1), 45-60. http://dx.doi.org/10.1023/A:1022218403113 